\title{
Fresh Food Cold-Chain Logistics Requirement Element Classification Based on Kano and Failure Mode and Effect Analysis (FMEA)
}

\author{
Yi Wang ${ }^{1, *}$ Yao Feng ${ }^{1}$
}

\author{
${ }^{1}$ School of Information Engineering, Jiangsu University of Science and Technology of Economics \& Management, \\ Zhenjiang, Jiangsu 215600, China \\ *Corresponding author. Email: 1558025937@qq.com
}

\begin{abstract}
In view of the subjectivity of traditional Kano model when analyzing data, the existing methods of Kano and failure mode and effect analysis (FMEA) were integrated to define the accurate requirement classification curve of Kano model. Then the risk priority number (RPN) value was calculated to determine the priority of preventive measures based on the optimization of parameter $\mathrm{K}$. Finally, the feasibility and effectiveness of accurate classification of customer requirements were verified by empirical research, and the priority of requirement for the fresh food cold-chain enterprises to improve customer satisfaction was determined, and corresponding strategies were given, which was of guiding significance to enhance the competitiveness of the fresh food cold-chain e-commerce enterprises.
\end{abstract}

Keywords: Kano model, FMEA, requirement classification, fresh food cold-chain

\section{INTRODUCTION}

Since the launch of taobao fresh food products special event in June 2011 to officially sell fresh food products, large e-commerce platforms have entered the fresh food market and adopted the whole-process coldchain logistics delivery mode, creating a new situation of fresh food agricultural products sales, and ushered in explosive growth in 2014-2015.

Noriaki Kano, professor of Tokyo institute of technology, a famous quality management expert in Japan, proposed the concept of Kano model through the in-depth investigation of Herzberg's two-factor theory, in order to analyze the influence of user requirement on user satisfaction. Based on the decision-making process of logistics service quality improvement based on the analytical Kano model, the specific application problems of the model are studied from an empirical perspective [1]. Aiming at the defects of the traditional fault mode and impact analysis (FMEA) method, Liu huchen proposed an improved FMEA model and applied it to the risk analysis of the actual cold-chain logistics distribution process [2]. It is found that there are few studies on Kano model and FMEA in fresh food cold-chain at present. Therefore, this paper studies the customer requirement classification problem of fresh food cold-chain based on KANO and FMEA integrated method.

\section{THEORETICAL MODEL}

\section{A. Kano model}

In 1984 Dr Noriaki Kano and his colleagues developed the Kano model. According to the nonlinear relationship between different types of requirement characteristics and customer satisfaction, Kano model divides the requirement characteristics of products or services into 5 categories [3]: Attractive requirements, One-dimensional requirements, Must-be requirements, Indifferent requirements and Reverse requirements.

The preliminary results of customer evaluation were obtained through the questionnaire of Kano model, and a requirement was classified by the positive and negative responses of customers.

The answer of each question in the questionnaire is compared with the classification table of Kano model, the probability of each requirement is obtained, and the highest frequency is taken as the final classification standard of the attribute.

\section{B. FMEA model}

T FMEA (failure mode and effect analysis) is the failure mode and effect analysis in product design phase and process manufacturing design phase.

The risk priority (RPN) in FMEA consists of three indicators, whose formulation will affect the calculation of RPN. The three indicators are severity (S), 
occurrence degree $(\mathrm{O})$, difficulty detection (D), and risk priority number (RPN) is the product of the three, such as formula (1):

$$
R P N=S \times O \times D_{(1)}
$$

he scores of $\mathrm{S}, \mathrm{O}, \mathrm{D}$ are in the range of $1-10$, indicating that the value of RPN is in the range of 11000. The higher the value of RPN, the higher the risk level [4].

\section{RESEARCH METHODS}

The exploratory case study of Shahin (2004) shows that the customer requirements determined by the traditional RPN method and the customer requirements determined by the traditional Kano model have different results, so Shahin's research integrates the Kano model and FMEA [5].

Shahin (2004) calculated the modification of RPN value based on the earlier studies of Tan and Shen (2000), and defined the satisfaction with the Kano model [6], as shown in formula (2):

$$
s=c p^{k}(2)
$$

$\mathrm{s}$ and $\mathrm{p}$ represent customer satisfaction and performance realization level respectively, $\mathrm{c}$ is a constant, and $\mathrm{k}$ is the Kano parameter. Shahin proposed that severity (S) could replace satisfaction (s) and failure rate $(\mathrm{O})$ could replace performance to achieve level (p). He also suggested that difficulty detection (D) be assumed to be independent of $\mathrm{S}$ and $\mathrm{O}$. The calculation of RPN is shown in formula (3):

$$
S=D O^{k} \rightarrow R P N=D \times S \times O=D \times D O^{k} \times O=D^{2} O^{k+1}
$$

Shahin also modified the calculation of the correction ratio $(\mathrm{Cr})$, which represents the "effort" from the current RPN0 to the target (RPNTg). He pointed out that if the detection is assumed to remain constant, the formula (4) for the correction ratio is as follows:

$$
C_{r}=1-\frac{R P N_{T g}}{R P N_{0}}=1-\frac{D_{T g}^{2} O_{T g}^{k+1}}{D_{0}^{2} O_{0}^{k+1}}=1-\left(\frac{O_{T g}}{O_{0}}\right)^{k+1}
$$

Shahin can also improve the accuracy of RPN output value through integration.

The research methods adopted in this paper are Madzík [7] based on the research of Shahin (2004) and Tan and Shen (Tan \& Shen, 2000).

\section{A. Defining the precise classification curve required by the Kano model}

The Kano questionnaire consists of one pair of pairs of questions. Each requirement can be classified by using the graph in the $5 \times 5$ grid of the Kano evaluation table. Madzik, p., \& Pelantova, v. (2018) found that using the standard Kano framework and the modified Kano evaluation table, the curves of each requirement type could be seen more accurately [8].

The data of the Kano questionnaire can be calculated according to the corresponding average starting and ending points of each customer's requirement, and then the average curve of each requirement can be obtained.

\section{$B$. Improving the parameter $K$ to calculate the $R P N$ value}

The RPN value is optimized by improving the index $\mathrm{k}$ in formula (2). Since The $\mathrm{k}$ parameter in formula 2 performs this function. Therefore, this paper determines the $\mathrm{k}$ parameter according to formula (5):

$$
k=\frac{4 \times D_{i_{\text {area }}}}{D_{\text {area }}}
$$

Where Di area is an area that is enclosed by the boundary of zero satisfaction and zero dissatisfaction where the curve $f \mathrm{i}$ is required to pass in coordinates, while D area is an area of overall dissatisfaction. In order to simplify the calculation, the curve can be drawn as a straight line, which reduces the difficulty of calculating Di area and reduces the error.

Therefore, assuming the coordinate system is $4 \times 4$ quadrants, the calculation process can be divided into four steps :(a) determine the average starting and ending points of each customer requirement curve $f \mathbf{i}$; (b) simplified generated curves; (c) calculate the area of Di area; (d) calculate k parameter according to formula 5 .

\section{Prioritizing preventive measures}

Since it is not certain whether the effort to implement preventive measures is less than or equal to the effect produced, in addition to determining the RPN value of the risk, preventive measures can also be evaluated according to the $\mathrm{Cr}$ value of the ratio of effort value to effect value, as shown in formula (6).

The effort value represents the total financial, time, and human resources required to implement the preventive measures. In the Kano model, the effort value can be defined as the distance between no implementation requirements and full implementation requirements. Effective values represent the distance between very dissatisfied and zero dissatisfied.

$$
C r=\frac{C R_{i} \text { Effort }}{C R_{i} \text { Effect }}
$$




\section{EMPIRICAL RESEARCH}

The following uses cold fresh food under the new retail as an example to study the customer requirements in the fresh food cold-chain based on the integrated method of Kano and FMEA.

\section{A. Questionnaire design and data collection}

The questionnaire is divided into two parts. The first part of the questionnaire is the information related to the humanistic statistical characteristics of customers, and the second part is the survey on the requirements of cold and fresh food customers. The questionnaire consisted of 10 pairs of questions. 100 questionnaires were distributed, and 74 valid responses were obtained. A total of 10 customer requirements were determined ( $\mathrm{f}$ i), as shown in "Table I".

The respondents were randomly selected from the customer base of a fresh food cold-chain e-commerce company and conducted surveys in two forms: E-mail and face-to-face. A total of 200 questionnaires were distributed on December 31, 2019 (1 solstice, 2019). A total of 178 questionnaires were finally collected, among which 152 were valid questionnaires, with an effective recovery rate of $76 \%$.

TABLE I. AVERAGE STARTING AND ENDING POINTS FOR EACH REQUIREMENT

\begin{tabular}{|c|c|c|}
\hline $\begin{array}{c}\text { Customer } \\
\text { requirement } \\
\text { code }\end{array}$ & Customer requirements & $\begin{array}{l}\text { Traditional } \\
\text { Kano } \\
\text { classification }\end{array}$ \\
\hline$f 1$ & $\begin{array}{l}\text { The delivery price is based on the } \\
\text { market price }\end{array}$ & $\mathrm{M}$ \\
\hline$f^{2}$ & Fresh food delivery with low loss & $\mathrm{M}$ \\
\hline$f 3$ & Logistics information tracking & $\mathrm{O}$ \\
\hline$f^{4}$ & $\begin{array}{l}\text { Fresh food platform or public number } \\
\text { every day there are preferential } \\
\text { activities }\end{array}$ & $\mathrm{A}(\mathrm{O})$ \\
\hline$f 5$ & $\begin{array}{l}\text { Install the community refrigerator pick } \\
\text { up }\end{array}$ & $\mathrm{M}$ \\
\hline$f^{6}$ & door-to-door service & $\mathrm{A}(\mathrm{O})$ \\
\hline$f 7$ & Buy Today Service Today & $\mathrm{A}(\mathrm{O})$ \\
\hline$f 8$ & Appointment next day service & $\mathrm{A}$ \\
\hline$f^{9}$ & After-sales service with easy return & $\mathrm{O}$ \\
\hline$f 10$ & Cold-chain & $\mathrm{O}$ \\
\hline
\end{tabular}

\section{B. Application based on the integration method of Kano and FMEA}

Through the results of the questionnaire, using the revised kano evaluation form, different customer requirements were assigned to 25 categories and the starting point and end point of the curve were defined for each requirement. 10 customer requirements were calculated by calculation. The average starting point and ending point are shown in "Table II", and the curve is shown in "Fig. 1".

TABLE II. AVERAGE STARTING POINT AND ENDING POINTS

\begin{tabular}{|l|l|l|}
\hline $\mathbf{f ~ i}$ & \multicolumn{1}{|c|}{$\begin{array}{c}\text { Average } \\
\text { starting point }\end{array}$} & \multicolumn{1}{c|}{$\begin{array}{c}\text { Average } \\
\text { ending point }\end{array}$} \\
\hline $\boldsymbol{f} \mathbf{1}$ & 8.57 & 4.53 \\
\hline $\boldsymbol{f} \mathbf{2}$ & 9.55 & 4.57 \\
\hline $\boldsymbol{f 3}$ & 7.30 & 4.47 \\
\hline $\boldsymbol{f} \mathbf{4}$ & 7.08 & 4.42 \\
\hline $\boldsymbol{f ~ 5}$ & 8.84 & 4.88 \\
\hline $\boldsymbol{f} \mathbf{6}$ & 7.47 & 4.30 \\
\hline $\boldsymbol{f} \mathbf{7}$ & 7.03 & 4.14 \\
\hline $\boldsymbol{f} \mathbf{8}$ & 6.97 & 4.23 \\
\hline $\boldsymbol{f} \mathbf{9}$ & 7.24 & 4.43 \\
\hline $\boldsymbol{f} \mathbf{1 0}$ & 7.35 & 4.39 \\
\hline
\end{tabular}




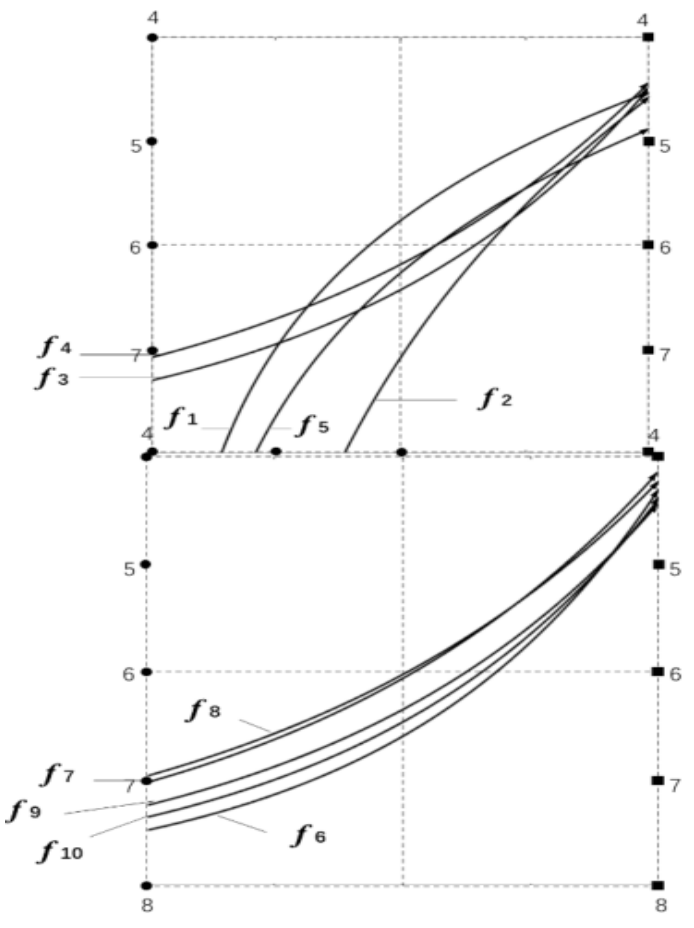

Fig. 1. Resulting requirement curves.

The average starting point and ending point of the 10customer request curves are determined, and the parameter $\mathrm{k}$ in the RPN value can be calculated through the process shown in "Fig. 1". The parameter $\mathrm{k}$ is incorporated into the RPN calculation, and the values of $\mathrm{D}$ and $\mathrm{O}$ are scored by experts. The RPN value calculated by the integrated method of Kano and FMEA, where S, D, and O represent the severity of the impact of the customer request on the customer, and the difficulty of finding out the problem of the customer request and the possibility of the problem.

The next is to calculate the $\mathrm{Cr}$ value, which is the ratio of the effort value to the effect value. The next is to put the effort and effect values required by 10 customers into a matrix to determine the priority of the preventive measures taken to meet the requirements, as shown in "Fig. 2".

The RPN value is the key to determining the priority of preventive measures, but the $\mathrm{Cr}$ value must be considered. Requirements with a higher RPN value ("Table III") and requirements with a lower $\mathrm{Cr}$ value that have a higher value should be given priority.

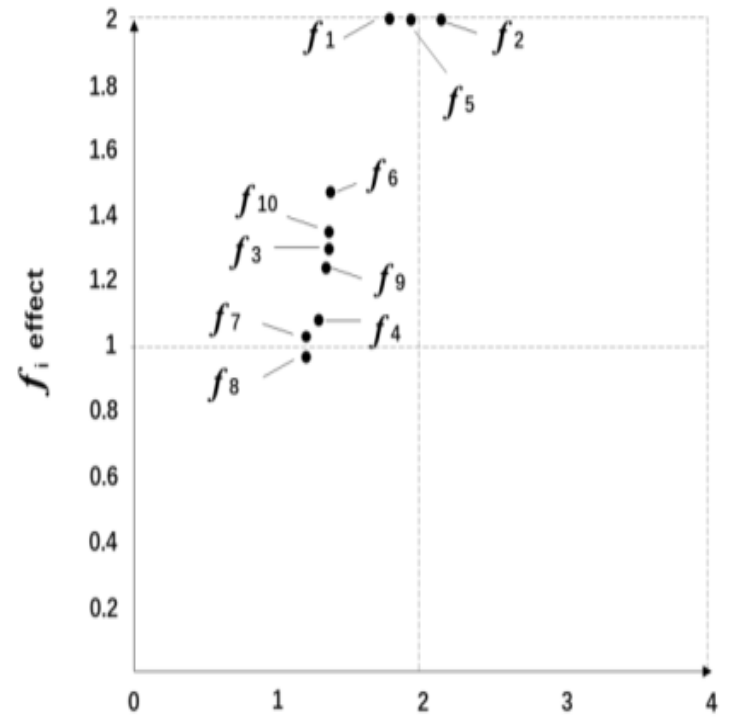

Fig. 2. Prioritization of preventive measures.

TABLE III. RPN CALCULATION

\begin{tabular}{|l|l|l|l|l|l|l|l|l|}
\hline $\mathbf{f} \mathbf{i}$ & $\begin{array}{c}\text { Starting point in } \mathbf{4} \times \mathbf{4} \\
\text { matrix }[\mathbf{x} ; \mathbf{y}]\end{array}$ & $\begin{array}{c}\text { Ending point in } \mathbf{4} \times \mathbf{4} \\
\text { matrix }[\mathbf{x} ; \mathbf{y}]\end{array}$ & $\mathbf{D} \mathbf{i}$ area & $\mathbf{K}$ & $\mathbf{S}$ & $\mathbf{D}$ & $\mathbf{O}$ & $\begin{array}{c}\mathbf{R P N}= \\
\mathbf{D} 2 \mathrm{OK}+\mathbf{1}\end{array}$ \\
\hline $\boldsymbol{f} \mathbf{1}$ & {$[0.57,0]$} & {$[4,3.47]$} & 3.12 & 1.56 & 2 & 3 & 3 & 150 \\
\hline $\boldsymbol{f} \mathbf{2}$ & {$[1.55,0]$} & {$[4,3.43]$} & 4.53 & 2.27 & 3 & 3 & 2 & 87 \\
\hline $\boldsymbol{f 3}$ & {$[0,0.70]$} & {$[4,3.53]$} & 1.19 & 0.60 & 4 & 2 & 3 & 23 \\
\hline $\boldsymbol{f} \mathbf{4}$ & {$[0,0.92]$} & {$[4,3.58]$} & 0.88 & 0.44 & 4 & 2 & 4 & 29 \\
\hline $\boldsymbol{f 5}$ & {$[0.84,0]$} & {$[4,3.12]$} & 3.7 & 1.85 & 6 & 2 & 3 & 92 \\
\hline $\boldsymbol{f} \mathbf{6}$ & {$[0,0.53]$} & {$[4,3.70]$} & 1.36 & 0.68 & 5 & 2 & 3 & 25 \\
\hline $\boldsymbol{f} \mathbf{7}$ & {$[0,0.97]$} & {$[4,3.86]$} & 0.73 & 0.37 & 5 & 3 & 3 & 40 \\
\hline $\boldsymbol{f} \mathbf{8}$ & {$[0,1.03]$} & {$[4,3.77]$} & 0.69 & 0.35 & 3 & 2 & 2 & 10 \\
\hline $\boldsymbol{f} \mathbf{9}$ & {$[0,0.76]$} & {$[4,3.57]$} & 1.09 & 0.55 & 4 & 3 & 2 & 26 \\
\hline $\boldsymbol{f ~ 1 0}$ & {$[0,0.65]$} & {$[4,3.61]$} & 1.23 & 0.62 & 4 & 2 & 3 & 24 \\
\hline
\end{tabular}


TABLE IV. CR CALCULATION

\begin{tabular}{|l|l|l|l|l|l|}
\hline $\mathbf{f} \mathbf{i}$ & Effect & Effort & $\mathbf{C r}$ & RPN & $\begin{array}{l}\text { RPN } \\
\text { Rank }\end{array}$ \\
\hline $\boldsymbol{f} \mathbf{1}$ & 2.00 & 1.77 & 0.89 & 150 & 1 \\
\hline $\boldsymbol{f} \mathbf{2}$ & 2.00 & 2.13 & 1.07 & 87 & 3 \\
\hline $\boldsymbol{f 3}$ & 1.30 & 1.35 & 1.04 & 23 & 9 \\
\hline $\boldsymbol{f} \mathbf{4}$ & 1.08 & 1.28 & 1.19 & 29 & 5 \\
\hline $\boldsymbol{f} \mathbf{5}$ & 2.00 & 1.92 & 0.96 & 92 & 2 \\
\hline $\boldsymbol{f} \mathbf{6}$ & 1.47 & 1.36 & 0.93 & 25 & 7 \\
\hline $\boldsymbol{f} \mathbf{7}$ & 1.03 & 1.19 & 1.16 & 40 & 4 \\
\hline $\boldsymbol{f} \mathbf{8}$ & 0.97 & 1.19 & 1.23 & 10 & 10 \\
\hline $\boldsymbol{f} \mathbf{9}$ & 1.24 & 1.33 & 1.07 & 26 & 6 \\
\hline $\boldsymbol{f} \mathbf{1 0}$ & 1.35 & 1.35 & 1.00 & 24 & 8 \\
\hline
\end{tabular}

\section{Results analysis}

From the above, the main difference between the traditional Kano model classification and the Kano model classification in this article is the data processing method and classification method, and the questionnaire design is consistent.

It can be seen from Table 1 that, $\mathrm{f} 4$, $\mathrm{f} 6$, and $\mathrm{f} 7$ are required to be between $\mathrm{A}$ and $\mathrm{O}$. With reference to "Table IV" and "Fig. 1", it can be seen that the Cr value of $\mathrm{f} 6$ is higher and has a higher required value. $\mathrm{f} 7$ and $\mathrm{f}$ 4 are between the two. These three requirements are listed in "Table IV" as $\mathrm{f} 7$ forth, $\mathrm{f} 4$ fifth, and $\mathrm{f} 6$ seventh. These three requirements rank thirdth in $\mathrm{f} 6$. Therefore, the classification of $\mathrm{f} 6$ is a charm requirement and can be resolved later. For the classification of $\mathrm{f} 4$ and $\mathrm{f} 7$ requirements, $\mathrm{f} 4$ 's requirement value is slightly higher than $f 7$, but $f$ 7's RPN value and ranking are slightly higher than $\mathrm{f} 4$, so these two requirements fluctuate between charm requirements and one-dimensional requirements. Table 4 also shows that the mandatory requirements $\mathrm{f} 1$ and $\mathrm{f}$ 2 have a strong customer attention.

\section{CONCLUSION}

Based on the above analysis, the cold-chain ecommerce industry should improve the level of customer satisfaction from the following aspects. First, the next-day delivery service is charm requirement in this case. The enterprise can spend less total finance, time and human resources Reap higher returns. Second, efficient distribution, timely logistics information tracking, the whole cold-chain and after-sales service with easy return and exchange are one-dimensional requirements. It's necessary to improve the quality of these requirements. Third, the distribution price is based on the market price, the low consumption of fresh food distribution and the self-explanation of the community freezer. These three requirements are the basic requirements for fresh food cold-chain ecommerce companies to obtain high performance and maintain old customers, so companies need to focus on improving the functional attributes of these service requirements. Fourth, today's purchase of today's service is between the charm requirement and the onedimensional requirement. The enterprise needs to adjust the solution according to the two requirements of different time periods and the value of customers.

\section{References}

[1] Meng, Q., \& Zou, N. (2012). A Decision Method for Improving Logistics Service Quality Based on Analytical KANO Model. OPERATIONS RESEARCH AND MANAGEMENT SCIENCE, 21(02), 64-73.

[2] Liu, H., \& Liu, R. (2018). Risk Analysis of Cold-chain Logistics Distribution Based on an Improved FMEA Method. Storage and Process, 018(4), 119-125

[3] Kano, N., Seraku, N., Takahashi, F., \& Tsuji, S. (1984) Attractive Quality and Must-Be Quality. JOURNAL OF THE JAPANESE SOCIETY FOR QUALITY CONTROL, 14(2), 39 48.

[4] Nair, A. (2006). Meta-Analysis of the Relationship Between Quality Management Practices and Firm PerformanceImplication for Quality Management Theory Development. Journal of Operations Management, 24(6), 948-975.

[5] Shahin, A. (2004). Integration of FMEA and the Kano model. International Journal of Quality \& Reliability Management, 21(7), 731-746

[6] Tan, K. C., \& Shen, X. X. (2000). Integrating Kano's model in the planning matrix of quality function deployment. Total Quality Management \& Business Excellence, 11(8), 0-0.

[7] Madzik P, Pelantova V. Validation of product quality through graphical interpretation of the Kano model[J]. International Journal of Quality \& Reliability Management, 2018, 35(9) 1956-1975.

[8] Madzik P, Kormanec P. Developing the integrated approach of Kano model and Failure Mode and Effect Analysis[J]. Total Quality Management \& Business Excellence, 2018: 1-23 